\title{
Copper(II) Inhibition of the SARS-CoV-2 Main Protease
}

\author{
Roberto A. Garza-López a, ${ }^{\text {a }}$ John J. Kozak ${ }^{\mathrm{b}}$ and Harry B. Gray ${ }^{\mathrm{c}}$
}

a) Department of Chemistry and Seaver Chemistry Laboratory, Pomona College, Claremont, CA 91711

b) Department of Chemistry, DePaul University, Chicago IL 60604-6116.

c) Beckman Institute, California Institute of Technology, Pasadena, CA 91125

\begin{abstract}
.
In an analysis of the structural stability of the coronavirus main protease (Mpro), we identified regions of the protein that could be disabled by cobalt(III)-cation binding to histidines and cysteines [1]. Here we have extended our work to include copper(II) chelates, which we have docked to HIS 41 and CYS 145 in the Mpro active-site region. We have found stable docked structures where $\mathrm{Cu}$ (II) could readily bond to the CYS 145 thiolate, which would be lethal to the enzyme.
\end{abstract}

\section{Introduction.}

Many investigators are searching for a therapeutic agent to treat coronavirus infections. One target that has received much attention is the SARS-CoV-2 main protease (Mpro) [1-17], a homodimer whose structure has been determined (Figure 1) [7]. Of relevance here is that the search for inhibitors has focused almost entirely on organic molecules. Surprisingly, there has been little attention paid to inorganic complexes, a void that we are working hard to fill. It is our view that metal ion binding to histidines and cysteines could be lethal to the protease [1]. 


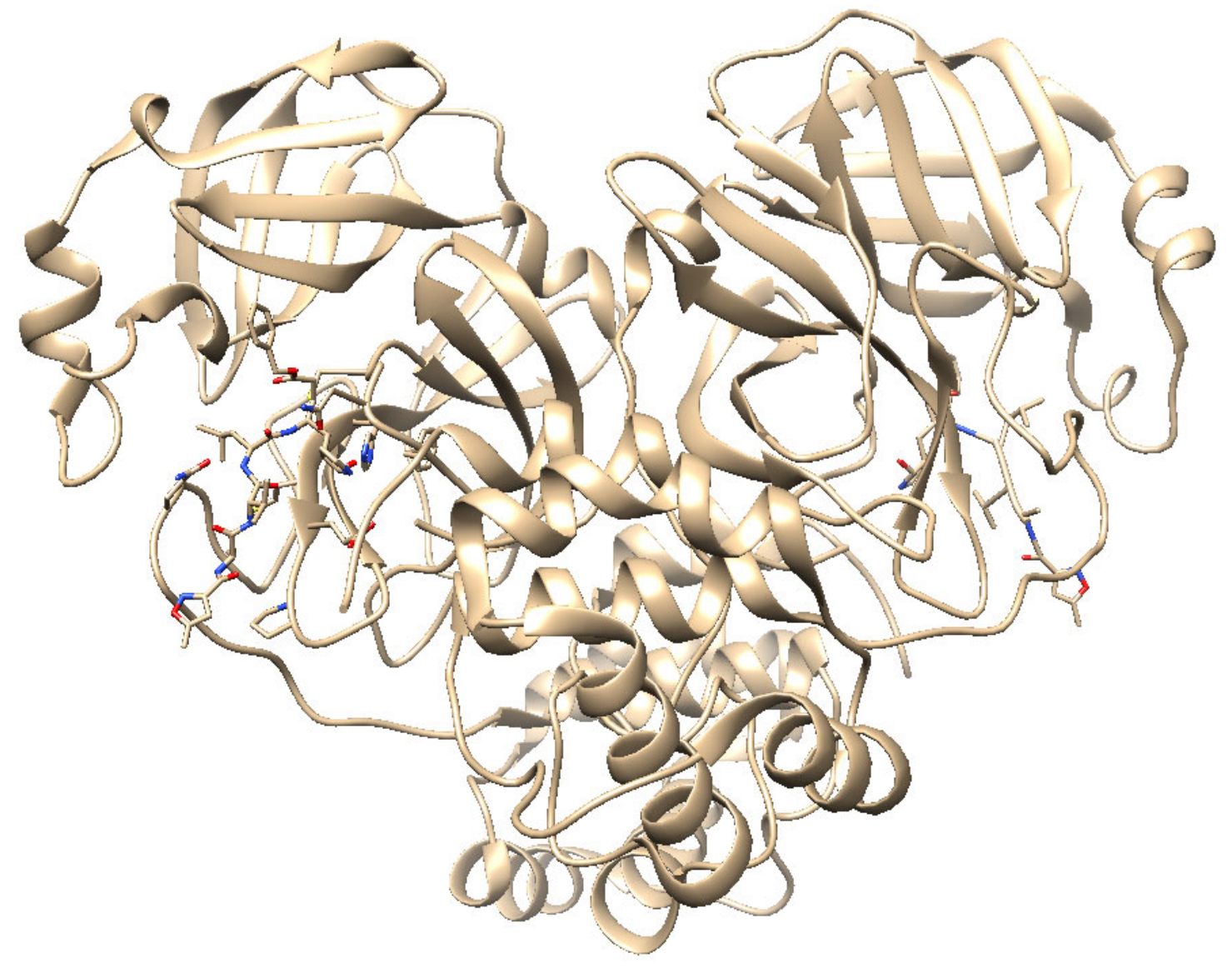

Figure 1. Chimera representation of the SARS-CoV-2 homodimer structure (PDB code: 6LU7).

\section{Metal-ion Binding.}

Of the seven histidines in the protease monomer, HIS 41 is in the most stable region of the native structure [1]. Metal-ion binding to the imidazole side chain of this histidine would break up the internal H-bond network (Figure 2), which would disable the enzyme. Other residues that could be targeted include HIS 163 and HIS 164, as they also are in relatively stable regions [1]. Among metal complex candidates that might bind in this region, $\left[\mathrm{Co}(\text { acacen })\left(\mathrm{NH}_{3}\right)_{2}\right]^{+}$is particularly attractive, as it is known to inhibit other proteases by HIS-imidazole displacement of one or both axial ammines $[18,19]$. 


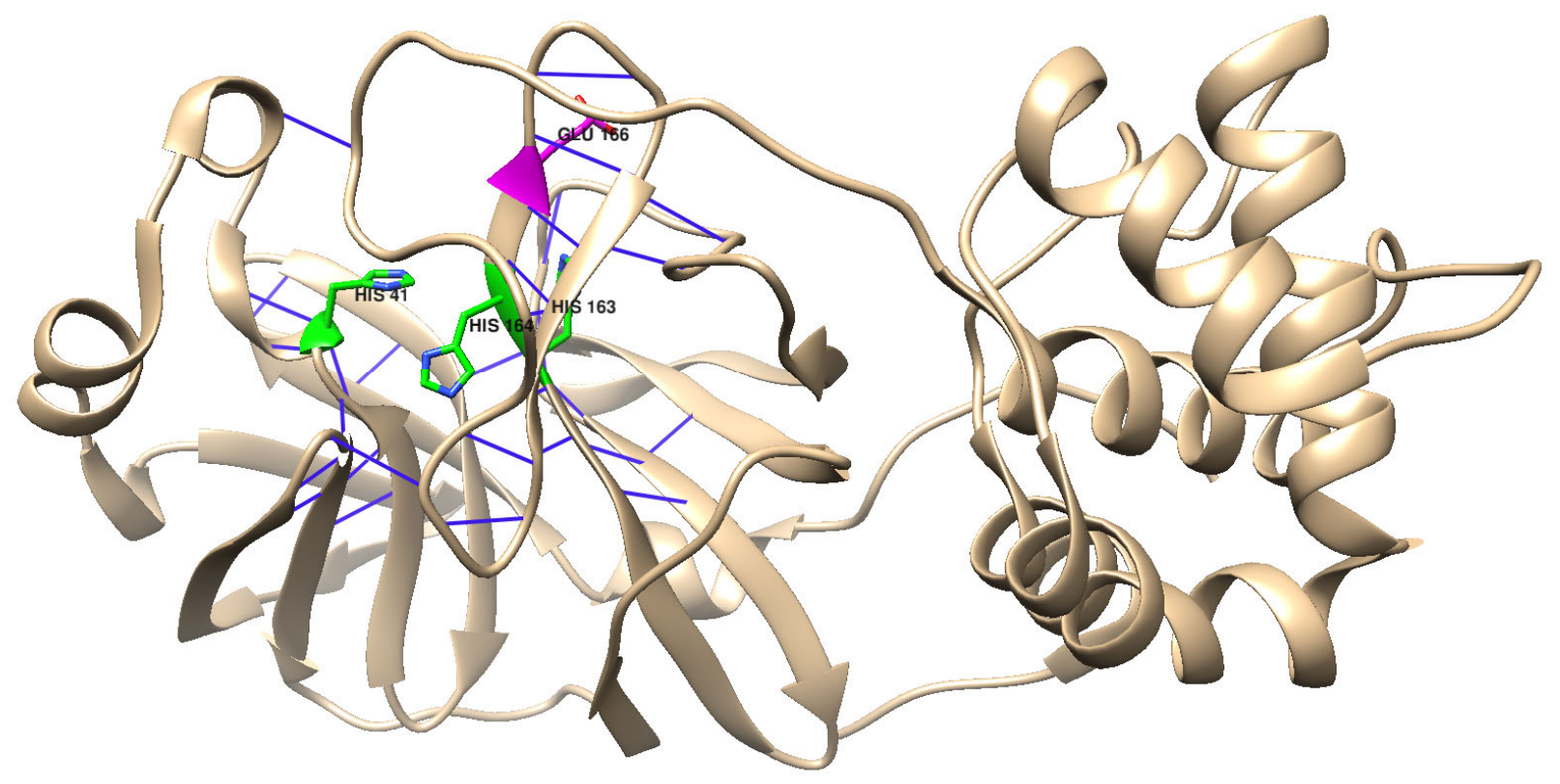

Figure 2. Chimera representation of the Mpro active-site H-bond network (blue lines); HIS 41, HIS 163, HIS 164, and GLU 166 are highlighted (PDB code 6Y2E).

We suggest that experiments using an excess of $\left[\mathrm{Co}(\text { acacen })\left(\mathrm{NH}_{3}\right)_{2}\right]^{+}$should be tried. If the protease is flooded with this cation, binding to at least 3 histidines could occur. Binding a cationic metal complex to several histidines would make the surface more hydrophilic, which in turn could trigger unfolding, as documented in our work on Co(III) binding to myoglobin [20].

In addition to experiments using an excess of [Co(acacen $\left.)\left(\mathrm{NH}_{3}\right)_{2}\right]^{+}$, other metal-ligand combinations could be effective. Particularly attractive are copper(II) complexes containing tridentate Schiff Base ligands (Figure 3), as they inhibit a thrombin protease [21]. 

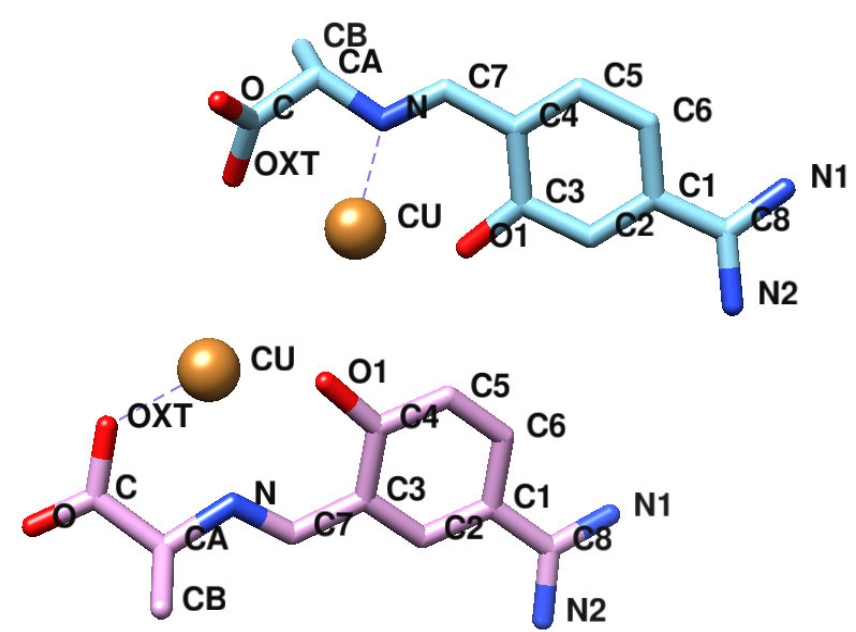

Figure 3. Structures of Schiff base copper(II) chelates:

top, [(para-amidinosalicylidene-1-alaninato)copper(II)], abbreviated $\mathrm{Cu}(\mathrm{II}) \mathrm{Lp}$; bottom, [(meta-amidinosalicylidene-1-alaninato)copper(II)], abbreviated $\mathrm{Cu}$ (II)Lm. Chimera graphics of the ligands $\mathrm{Cu}(\mathrm{II}) \mathrm{Lm}$ and $\mathrm{Cu}(\mathrm{II}) \mathrm{Lp}$ obtained from PDB ID's: $1 \mathrm{G} 3 \mathrm{D}$ and $1 \mathrm{G} 3 \mathrm{E}$ respectively [21].

We successfully docked $\mathrm{Cu}(\mathrm{II}) \mathrm{Lm}$ near HIS 41 in the active-site region of the enzyme. Among the low-energy $\mathrm{Cu}(\mathrm{II}) \mathrm{Lm} / \mathrm{Mpro}$ conjugates, one places the $\mathrm{Cu}$ atom near the CYS 145 thiolate sulfur at a distance $(\mathrm{Cu}-\mathrm{S})=2.89 \AA$ (Figure 4). [The $\mathrm{Cu}-\mathrm{S}$ distance is $3.472 \AA$ in the lowest energy docked structure (Figure S1).] In all docked structures near HIS 41, it is likely that protein motions would allow $\mathrm{Cu}(\mathrm{II})$ to bond directly to the CYS 145 thiolate, which in turn would be lethal to the protease. To explore steric effects on $\mathrm{Cu}(\mathrm{II}) \mathrm{Lm} / \mathrm{Mpro}$ interactions, we docked less bulky analogues, $\mathrm{Cu}(\mathrm{II}) \mathrm{Lm}$-methyl and $\mathrm{Cu}(\mathrm{II}) \mathrm{Lm}$-mini, into the CYS 145 site (Figures 5, S2, and S3). The two oxygen donors are tightly bonded to $\mathrm{Cu}(\mathrm{II})$ in these docked sites, with $\mathrm{Cu}-\mathrm{S}(\mathrm{CYS} 145)=3.11 \AA$ in the structure shown in Figure 5. [Other $\mathrm{Cu}-\mathrm{S}$ distances are $3.137 \AA$ (Figure S2) and $3.098 \AA ̊$ (Figure S3).] Once again, small conformational motions might trigger $\mathrm{Cu}(\mathrm{II})$ ligation to the CYS 145 thiolate, which would disrupt protease function. 


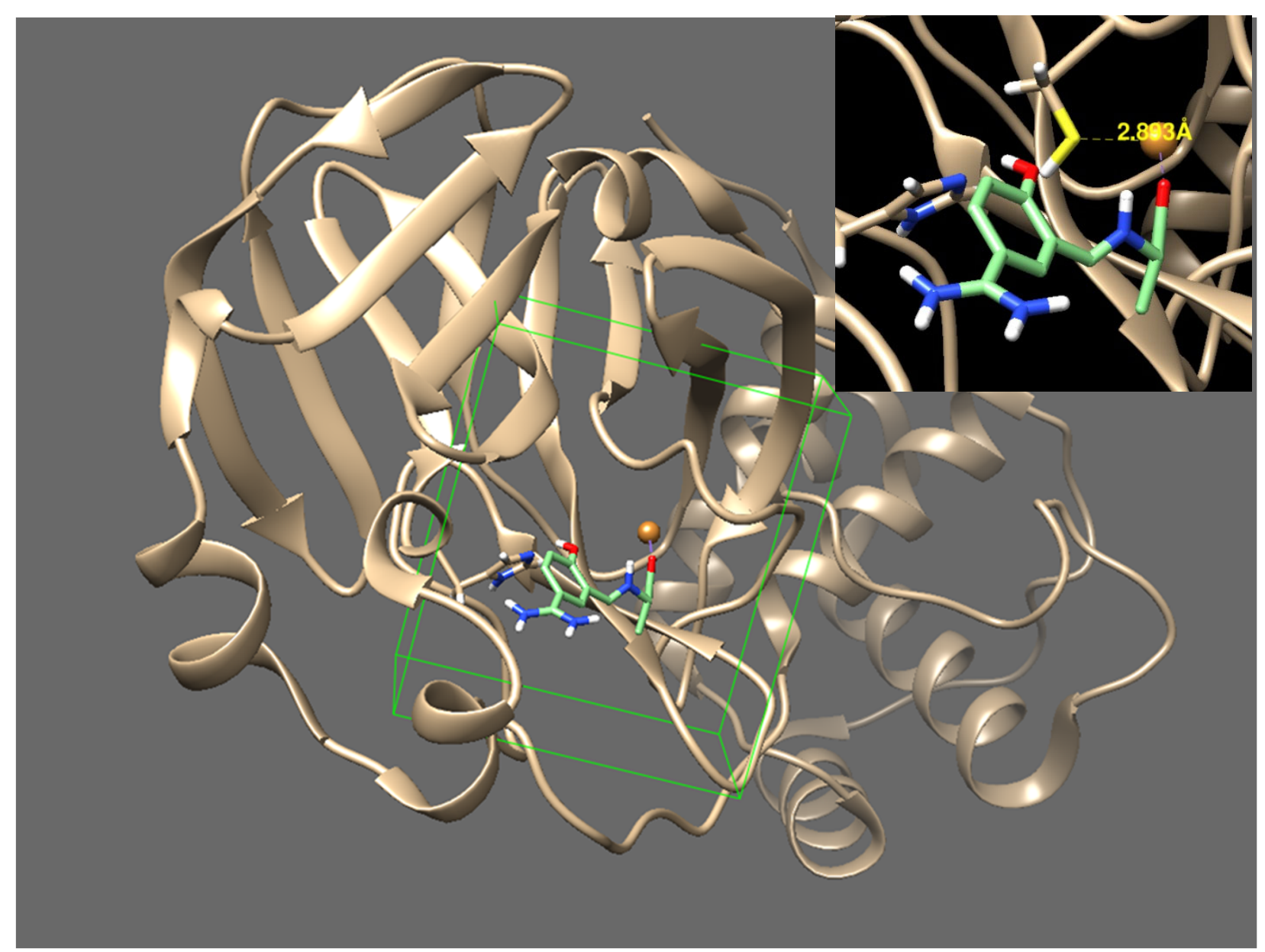

Figure 4. Chimera representation of $\mathrm{Cu}(\mathrm{II}) \mathrm{Lm}$ docked near HIS 41 in Mpro (PDB code 6Y2E). The inset shows the Cu-S(CYS 145) distance of $2.893 \AA$. The ligand and receptor files were prepared using the molecular docking program AutoDock Vina [22]. The amino acid HIS 41 is enclosed in the green box. AutoDock Vina predicts the bound conformations and the binding affinities $(\mathrm{kcal} / \mathrm{mol})$ within that space. The different poses were visualized via Chimera. 


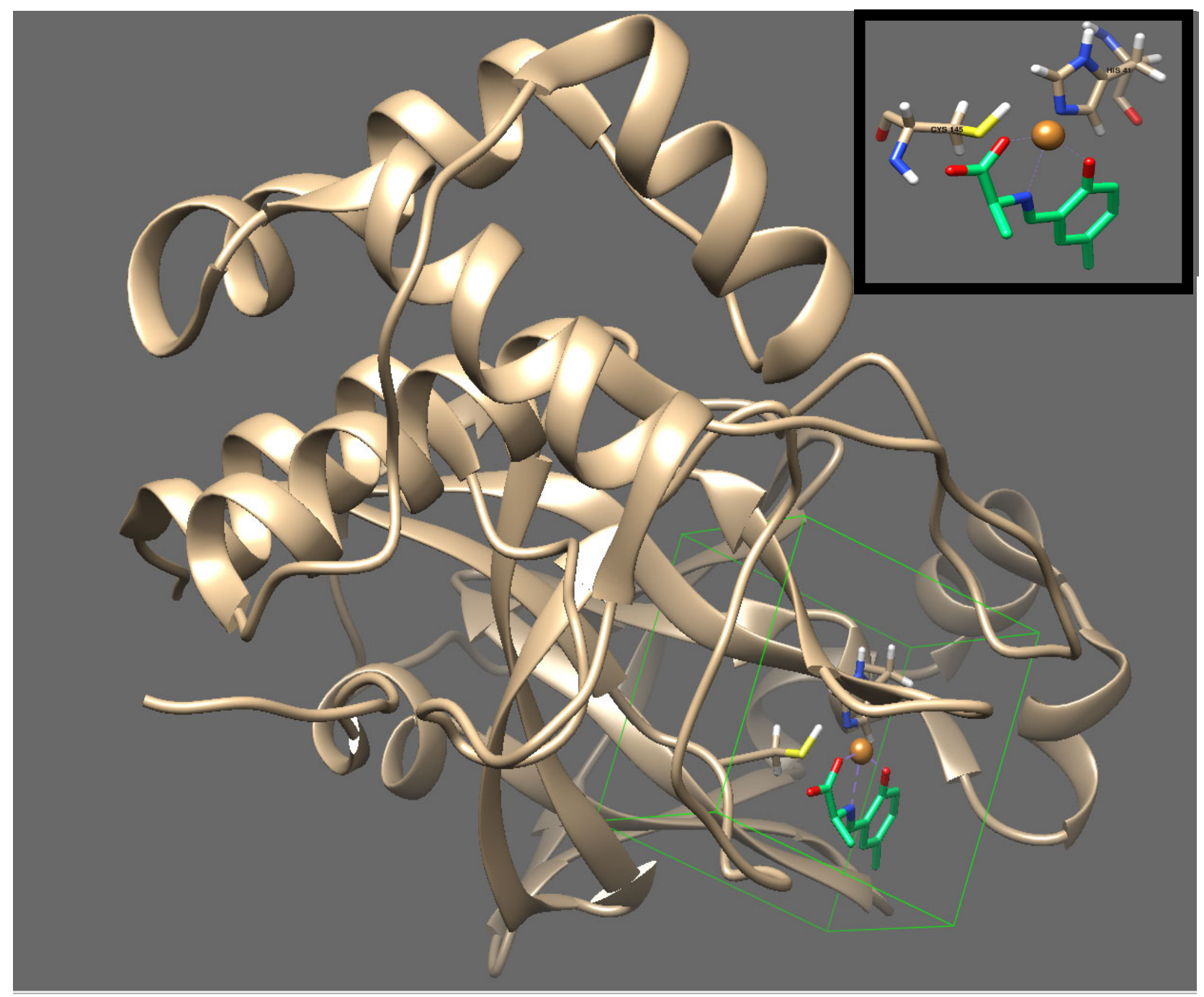

Figure 5. Chimera representation of $\mathrm{Cu}(\mathrm{II}) \mathrm{Lm}$-methyl docked near CYS 145 in Mpro (PDB code 6Y2E); $\mathrm{Cu}(\mathrm{II})$ is $3.11 \AA$ from the CYS 145 thiolate sulfur. The structure of Cu(II)Lm-methyl is shown in the inset. Docking details as in Figure 4.

Cobalt and copper ligation to cysteines other than CYS 145 also should be explored. Of the 12 cysteines in the protease monomer, arguably the most attractive target is CYS 44, which is on a very stable helix [1]. Displacement of an axial ammine in $\left[\mathrm{Co}(\text { acacen })\left(\mathrm{NH}_{3}\right)_{2}\right]^{+}$by the CYS 44 thiolate would trigger partial helical unfolding, which could disrupt protease function. 
We also are studying the Spike protein (Figure 6), a trimer with many cysteines and histidines that are exposed to solvent [23]. We are testing the proposal that cobalt(III) or copper(II) binding to these residues would partially unfold the protein, including the region around GLY 614 in the D614G mutant.

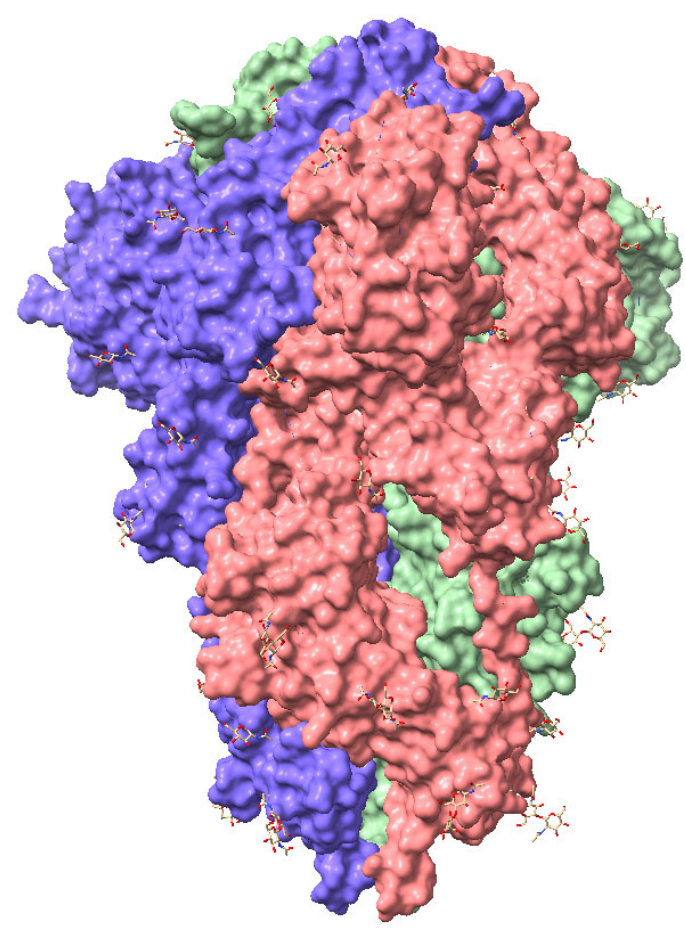

Figure 6. ChimeraX representation of SARS-CoV-2 spike glycoprotein (closed state), PDB ID: 6VXX. [23,24]

\section{Concluding Remarks.}

We have identified several very attractive histidine and cysteine targets for protease inhibiton by inorganic therapeutic agents. In one scenario, cobalt and copper binding to histidines could unfold the main protease. In others, the protease could be disabled by $\mathrm{Cu}-\mathrm{S}$ bonding in $\mathrm{Cu}(\mathrm{II}) \mathrm{Lm}$ conjugates. 


\section{Acknowledgements.}

Work at Caltech was supported by the Arnold and Mabel Beckman Foundation. Support at Pomona College was provided by the Howard Hughes Medical Institute Research Program and a Sontag Research Fellowship Award. Molecular graphics and analyses performed with UCSF Chimera, developed by the Resource for Biocomputing, Visualization, and Informatics at the University of California, San Francisco, with support from NIH P41-GM103311. Molecular graphics and analyses performed with UCSF ChimeraX, developed by the Resource for Biocomputing, Visualization, and Informatics at the University of California, San Francisco, with support from National Institutes of Health R01-GM129325 and the Office of Cyber Infrastructure and Computational Biology, National Institute of Allergy and Infectious Diseases. 


\section{REFERENCES}

[1] J.J. Kozak, H.B. Gray, R.A. Garza-López. Structural Stability of the SARS-CoV-2 Main Protease: Can Metal Ions Affect Function? J Inorg Biochem 16 July 2020, 111179. https://doi.org/10.1016/j.jinorgbio.2020.111179

[2] A. Belhassan, S. Chtita, H. Zaki, T. Lakhlifi, M. Bouachrine, Molecular docking analysis of N-substituted oseltamivir derivatives with the SARS-Cov-2 main protease, Bioinformation, 16 (2020) 404-408.

[3] S. Das, S. Sarmah, S. Lyndem, A. S. Roy, An investigation into the identification of potential inhibitors of SARS-CoV-2 main protease using molecular docking study, J. Biomol. Struct. Dyn., (2020) DOI: 10.1080/07391102.2020.1763201.

[4] D. Gentile, V. Patamia, A. Scala, M. T. Sciortino, A. Piperno, A. Rescifina, Putative Inhibitors of SARS-CoV-2 Main Protease from A Library of Marine Natural Products: A Virtual Screening and Molecular Modeling Study, Mar. Drugs, 18 (2020) 225.

[5] M. Hakmi, E. Bouricha, I. Kandoussi, J. El Harti, A. Ibrahimi, Repurposing of known anti-virals as potential inhibitors for SARS-CoV-2 main protease using molecular docking analysis, Bioinformation, 16 (2020) 301-305.

[6] R. Islam, M. R. Parves, A. S. Paul, N. Uddin, M. S. Rahman, A. Al Mamun, M. N. Hossain, M. A. Ali, M. A. Halim, A molecular modeling approach to identify effective antiviral phytochemicals against the main protease of SARS-CoV-2, Biomol. Struct. Dyn., (2020) DOI: 10.1080/07391102.2020.1761883.

[7] Z. M. Jin, X. Y. Du, Y. C. Xu, Y. Q. Deng, M. Q. Liu, Y. Zhao, et al., Structure of M-pro from SARS-CoV-2 and discovery of its inhibitors, Nature, 582 (2020) 289-293.

[8] R. S. Joshi, S. S. Jagdale, S. B. Bansode, S. S. Shankar, M. B. Tellis, V. K. Pandya, et al., Discovery of potential multi-target-directed ligands by targeting host-specific SARSCoV-2 structurally conserved main protease, J. Biomol. Struct. Dyn., (2020) DOI: 10.1080/07391102.2020.1760137.

[9] T. Joshi, T. Joshi, P. Sharma, S. Mathpal, H. Pundir, V. Bhatt, S. Chandra, In silica screening of natural compounds against COVID-19 by targeting Mpro and ACE2 using molecular docking, Eur. Rev. Med. Pharmaco., 24 (2020) 4529-4536.

[10] N. Lobo-Galo, M. Terrazas-Lopez, A. Martinez-Martinez, A. G. Diaz-Sanchez, FDAapproved thiol-reacting drugs that potentially bind into the SARS-CoV-2 main protease, essential for viral replication, J. Biomol. Struct. Dyn., (2020) DOI: 10.1080 / 07391102. 2020. 1764393 
[11] H. M. Mengist, X. J. Fan, T. C. Jin, Designing of improved drugs for COVID-19: Crystal structure of SARS-CoV-2 main protease M-pro, Signal Transduct. Tar., 5 (2020) 67.

[12] J. T. Ortega, M. L. Serrano, F. H. Pujol, H. R. Rangel, Unrevealing Sequence and Structural Features of Novel Coronavirus Using in Silico Approaches: The Main Protease as Molecular Target, Excli. Journal, 19 (2020), 400-409.

[13] M. H. Sampangi-Ramaiah, R. Vishwakarma, R. U. Shaanker, Molecular docking analysis of selected natural products from plants for inhibition of SARS-CoV-2 main protease, Curr. Sci. 118 (2020) 1087.

[14] P. Sang, S. H. Tian, Z. H. Meng, L. Q. Yang, Anti-HIV drug repurposing against SARSCoV-2, Rsc. Adv. 10 (2020) 15775-15783.

[15] L. L. Zhang, D. Z. Lin, X. Y. Y. Sun, U. Curth, C. Drosten, L. Sauerhering, et al., Crystal structure of SARS-CoV-2 main protease provides a basis for design of improved alphaketoamide inhibitors, Science 368 (2020) 409.

[16] U. C. Chaturvedi, R. Shrivastava, Interaction of viral proteins with metal ions: role in maintaining the structure and functions of viruses. Fems. Immunol. Med. Mic. 43 (2020) 105-114.

[17] A. Fischer, M. Sellner, S. Neranjan, M. Smieško, M. A. Lill, Potential Inhibitors for Novel Coronavirus Protease Identified by Virtual Screening of 606 Million Compounds. Int. J. Mol. Sci. 21 (2020) 3626.

[18] T. Takeuchi, A. Böttcher, C. M. Quezada, M. I. Simon, T. J. Meade, H. B. Gray. Selective Inhibition of Human $\alpha$-Thrombin by Cobalt(III) Schiff Base Complexes. J. Am. Chem. Soc. 120 (1998) 8555-8556.

[19] A. Böttcher, T. Takeuchi, K. I. Hardcastle, T. J. Meade, H. B. Gray, D. Cwikel, M. Kapon, Z. Dori. Spectroscopy and Electrochemistry of Cobalt(III) Schiff Base Complexes. Inorg. Chem. 36 (1997) 2498-2504.

[20] O. Blum, A. Haiek, D. Cwikel, Z. Dori, T. J. Meade, H. B. Gray. Isolation of a myoglobin molten globule by selective cobalt(III)-induced unfolding. Proc.. Natl Acad. Sci. USA 95 (1998) 6659-6662.

[21] E. Toyota, K. K.S Ng, H. Sekizaki, K. Itoh, K. Tanizawa, M. N.G. James. X-ray crystallographic analyses of complexes between bovine $\beta$-trypsin and schiff base copper(II) or iron(III) chelates. J. Mol. Biol. 305 (2001) 471-479. 
[22] O. Trott, A. J. Olson. Software News and Update AutoDock Vina: Improving the Speed and Accuracy of Docking with a New Scoring Function, Efficient Optimization, and Multithreading. J. Comput. Chem. 31 (2010) 455-461.

[23] A. C. Walls, Y-J. Park, M.A. Tortorici, A. Wall, A. T. McGuire, D. Veesler. Structure, Function, and Antigenicity of the SARS-CoV-2 Spike Glycoprotein, Cell, 181(2020)281292.

[24] T. D. Goddard, C. C. Huang, E. C. Meng, E. F. Pettersen, G. S. Couch, J. H. Morris, T. E. Ferrin. UCSF ChimeraX: Meeting modern challenges in visualization and analysis. Protein Sci. 2018 Jan;27(1):14-25. 
Supporting Information

Figure S1: Chimera representation of $\mathrm{Cu}$ (II)Lm docked near HIS 41 in Mpro (PDB code 6Y2E) with a binding energy of $6.8 \mathrm{kcal} / \mathrm{mol}$. Inset: $\mathrm{Cu}(\mathrm{II})$ chelation; $\mathrm{Cu}-\mathrm{S}(\mathrm{CYS} 145)=3.472 \AA$. The ligand and receptor files were prepared using the molecular docking program AutoDock Vina [22]. The amino acid HIS 41 is enclosed in the green box. AutoDock Vina predicts the bound conformations and the binding affinities $(\mathrm{kcal} / \mathrm{mol})$ within that space. The different poses were visualized via Chimera

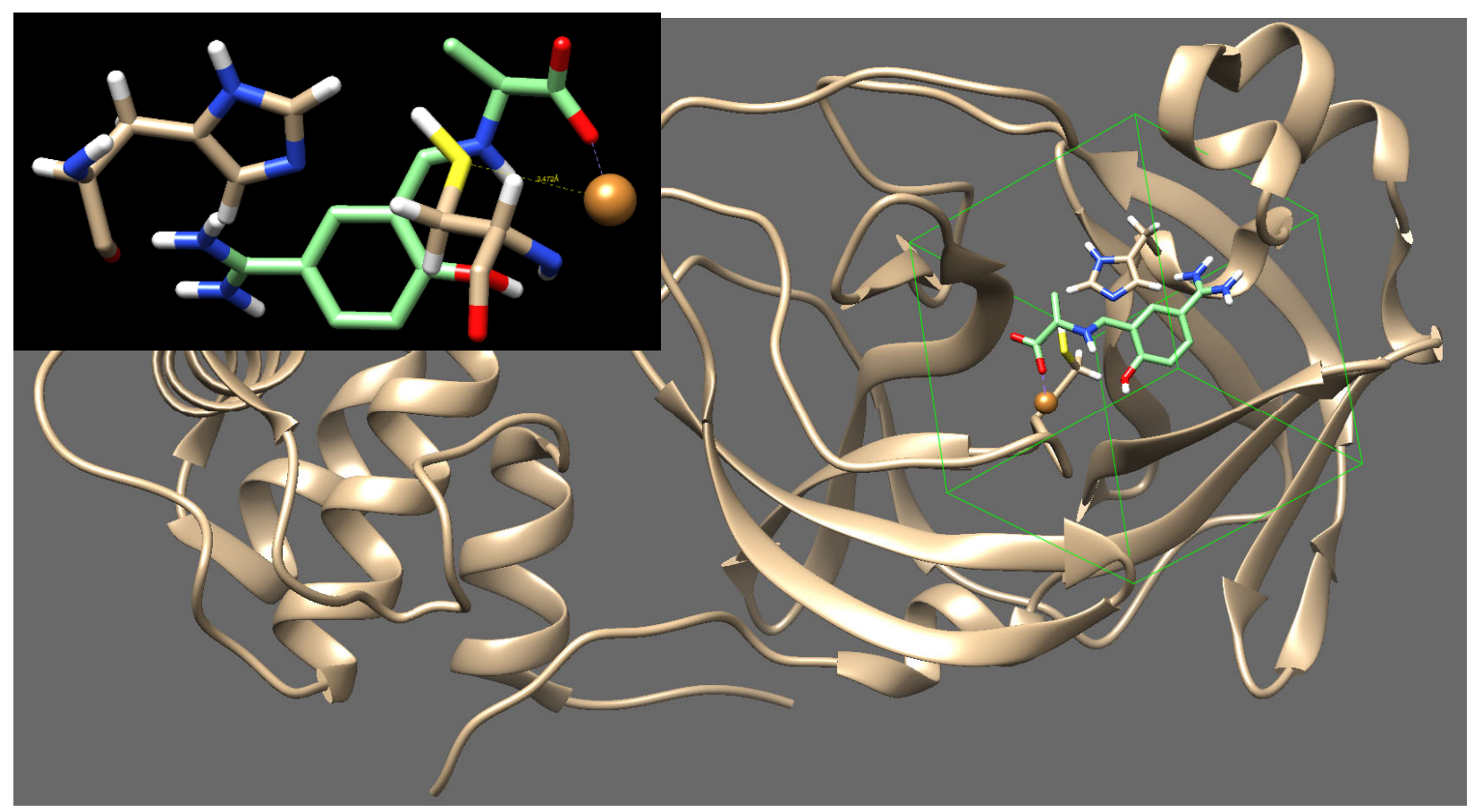


Figure S2. Chimera representation of $\mathrm{Cu}(\mathrm{II}) \mathrm{Lm}$-methyl docked near HIS 41 in Mpro (PDB code 6Y2E) with a docking energy of $7.2 \mathrm{kcal} / \mathrm{mol}$. Inset: $\mathrm{Cu}(\mathrm{II})$ chelation; $\mathrm{Cu}-\mathrm{S}(\mathrm{CYS} 145)=3.137$ $\AA$. The ligand and receptor files were prepared as in Fig. S1.

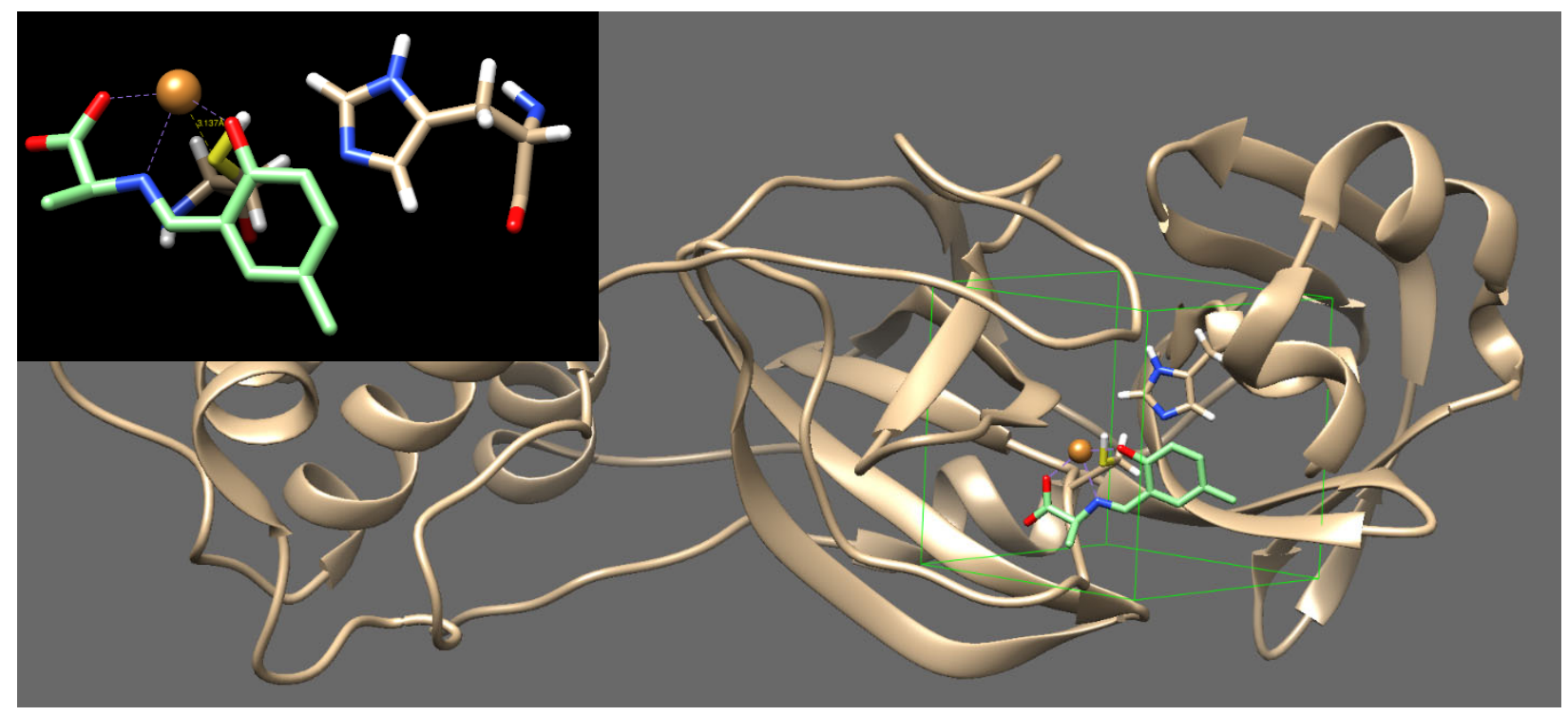

Figure S3: Chimera representation of $\mathrm{Cu}(\mathrm{II}) \mathrm{Lm}$-mini docked near HIS 41 in Mpro (PDB code 6Y2E) with a binding energy of $6.2 \mathrm{kcal} / \mathrm{mol}$. Inset: $\mathrm{Cu}(\mathrm{II})$ chelation; $\mathrm{Cu}-\mathrm{S}(\mathrm{CYS} 145)=3.098 \AA$. The ligand and receptor files were prepared as in Fig. S1.

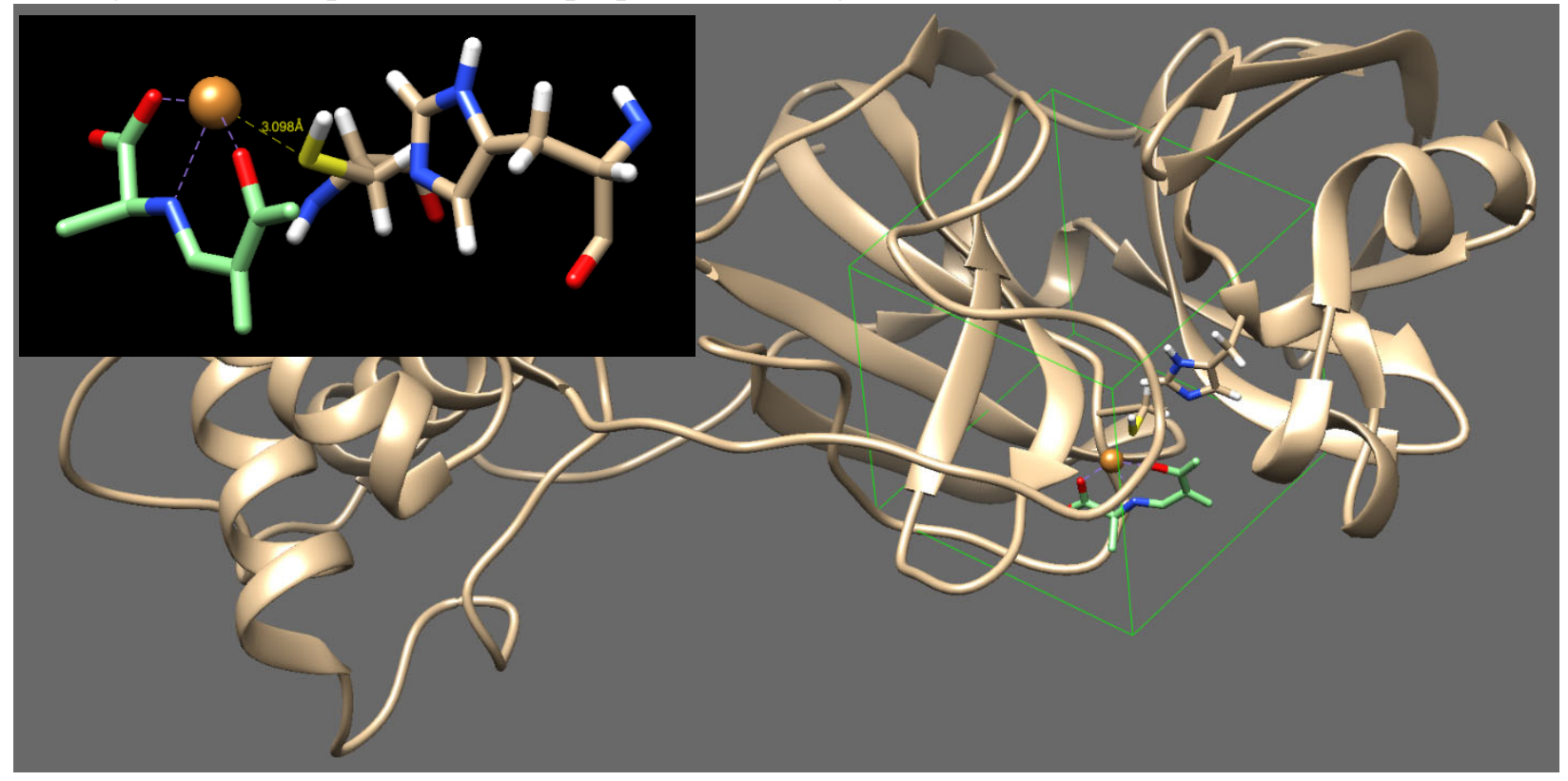

